\title{
Medical Management of Fecal Incontinence
}

\author{
YOLANDA SCARLETT \\ Division of Gastroenterology and Hepatology, University of North Carolina School of Medicine, Chapel Hill, North Carolina
}

Diarrhea and constipation are known risk factors for fecal incontinence. This report reviews how to diagnose and medically treat patients with chronic diarrhea, chronic constipation with overflow incontinence, and incontinence resulting from rectal mucosal prolapse secondary to hemorrhoids. Antidiarrheal agents (including loperamide, diphenoxylate, and difenoxin) and the tricyclic antidepressant amitriptyline improve continence in patients with diarrhea-associated incontinence. Other antidiarrheal agents are under investigation. The mechanism is believed to be decreased intestinal motility and stool frequency resulting in more formed stools. Increases in anal canal resting pressure may also contribute to improvement in continence. Adverse effects are constipation from excessive use. In addition to antidiarrheal drugs, fiber supplements may improve incontinence associated with diarrhea. Transient, benign cases of constipation usually respond to increasing fluid intake and dietary fiber, improving mobility, or eliminating the concurrent use of constipating drugs. For mild to moderate constipation, bulking agents, laxatives, and stool softeners are used cautiously so as not to excessively loosen stools and exacerbate anal incontinence. Laxatives have been shown to improve continence, possibly through the mechanism of eliminating fecal impaction. Prolapsing hemorrhoids may partially obstruct defecation and cause soilage from the passage of fecal material, mucus, or blood. With endoscopic banding, a ligator is attached to an endoscope and a tight band is placed around the enlarged vein, causing the hemorrhoid to thrombose.

Gecal incontinence is a condition with well-docu1 mented adverse physical, social, psychological, and economic consequences. Estimates of its prevalence, which range from $2 \%^{1}$ to $7 \%^{2}$ in the community-dwelling population to $45 \%$ or more ${ }^{3,4}$ among institutionalized persons, are probably low because of individual reluctance to discuss the embarrassing condition. $\mathrm{Pa}-$ tients report that fecal incontinence can have a devastating effect on employment, social interaction, self-esteem, and overall quality of life. , $6^{5}$

Diarrhea and constipation are recognized as independent risk factors of fecal incontinence, ${ }^{3,7,8}$ and the medical management of fecal incontinence is directed pri- marily toward the treatment of diarrhea and constipation. By contrast, surgical and behavioral treatments focus more on the strength of the pelvic floor muscles and the ability to perceive rectal filling in patients with fecal incontinence secondary to neurologic and anatomic defects. Medical management is frequently combined with surgical or behavioral treatment because constipation or diarrhea may exacerbate incontinence associated with neurologic and anatomic defects.

\section{Pathophysiology and Diagnosis}

Numerous medical conditions can affect the anatomy and function of the anorectal muscles and the pelvic floor and thereby place individuals at risk for fecal incontinence. Injuries associated with childbirth, anorectal surgery, anorectal trauma, inflammatory processes, and tumors are typical causes of anatomic sphincter muscle disruption. Pelvic floor muscle and anal sphincter denervation can result from injury during childbirth, neuropathy, spinal cord injury, and congenital abnormalities such as spina bifida and myelomeningocele. Neurologic conditions such as dementia, cerebrovascular accident, multiple sclerosis, tertiary syphilis, brain tumor, and cauda equina syndrome can also contribute to fecal incontinence.

Diarrhea and constipation are 2 common conditions that exacerbate fecal incontinence. Most cases of diarrhea result from disorders related to water and electrolyte transport in the intestinal tract. Excess secretion of electrolytes and water into the intestinal lumen, the loss of protein and fluid from the mucosa, and increased osmotic load in the intestine can alter intestinal motility and decrease stool transit time. The more common underlying pathologies associated with chronic diarrhea include irritable bowel syndrome (IBS), Crohn's disease, ulcerative colitis, small-bowel bacterial overgrowth, shortbowel syndrome, bile acid malabsorption, celiac disease, microscopic colitis, and diabetic diarrhea. Although con-

Abbreviations used in this paper: CNS, central nervous system; IBS, irritable bowel syndrome.

(C) 2004 by the American Gastroenterological Association 0016-5085/04/\$30.00 doi:10.1053/j.gastro.2003.10.007 
stipation is generally regarded as benign, chronic cases left untreated may lead to fecal impaction with overflow incontinence. Typical causes of constipation include lack of dietary fiber, immobility, neurogenic disorders, systemic illnesses, and medications.

This report focuses on how to properly diagnose and medically treat patients with chronic diarrhea (including that related to IBS), chronic constipation with overflow incontinence, and incontinence resulting from rectal mucosal prolapse secondary to hemorrhoids.

\section{Evaluating Patients and Choosing a Treatment Option}

Compiling a detailed medical history and performing a comprehensive examination can provide essential information to help guide the treatment of patients with fecal incontinence. Important facts to deduce from the patient history and examination are the total number of bowel movements and the number of incontinent episodes in a 7-day period, stool consistency and the volume of stool loss, awareness of stool passage, and whether the rectal vault is being completely evacuated. Fecal incontinence is rarely caused by a single factor, so diagnostic evaluation of the afferent and efferent innervation and structural muscle integrity of the external anal sphincter and pelvic floor may be necessary to pinpoint the underlying pathology..$^{9}$ Anorectal manometry, electromyography, pudendal nerve latency testing, and ultrasound imaging of the anal sphincter are used to evaluate motor function, nerve function, and anatomic structure of the pelvis. If the patient has constipation with overflow incontinence, the use of radiopaque colonic transit markers can help determine colonic transit time and identify marker retention patterns consistent with outlet obstruction. Defecography with soft barium paste can also render useful information about the anorectal angle, pelvic floor descent, and rectal prolapse that may contribute to fecal incontinence.

Ultimately, the aim of medical management is to identify and treat the underlying disorders causing diarrhea or constipation, relieve symptoms, restore bowel control, and improve quality of life. However, when these disorders cannot be identified or reversed, medical treatment is largely targeted toward providing symptom relief.

\section{Medical Management of Chronic Diarrhea}

Pharmacotherapy is usually reserved for patients with more persistent diarrhea that does not respond to conservative treatments such as bulking agents. Nonspe- cific antidiarrheal agents decrease intestinal motility and decrease stool frequency, which may in turn limit the number of incontinent episodes. Modifying stool consistency is also a primary goal, because formed stool is easier to control than loose stool. Practitioners should always be mindful of the possible constipating effects of excessive use of antidiarrheal agents.

\section{Loperamide}

A synthetic opioid with an excellent safety profile, loperamide has been found to be effective in treating traveler's diarrhea and acute diarrhea and has been used as an adjunctive treatment of nearly all forms of chronic diarrhea. Loperamide acts directly on the intestine to inhibit peristalsis, lengthens small intestinal and mouthto-cecum transit time, increases sphincter tone and resting pressure, and reduces urgency, stool volume, and frequency of bowel movements. ${ }^{10}$ Its mechanism of action is to increase mucosal contact time, allowing for more complete absorption of electrolytes and water. The antidiarrheal activity of loperamide may derive from its functioning as both a calcium receptor antagonist and a calcium channel blocker. ${ }^{11}$ Loperamide may also reduce the sensitivity of the rectoanal inhibitory reflex and increase rectal perception in healthy subjects. ${ }^{12}$ Loperamide does not cross the blood-brain barrier and has no addiction potential.

In a double-blind, crossover study of 30 subjects with chronic diarrhea, ${ }^{13}$ loperamide, codeine, and diphenoxylate decreased stool frequency to the same degree but loperamide and codeine were more effective than diphenoxylate in decreasing the sense of urgency that was often associated with fecal incontinence in these patients. Previous research ${ }^{14}$ suggested that loperamide improves control of urgency by increasing anal tone and improving colonic tolerance of fluid load introduced into the rectum. Palmer et al. reported that patients treated with diphenoxylate experienced more adverse effects, including central nervous system (CNS) symptoms. The investigators concluded that the primary drawback of loperamide was that it tended to be too potent and produced constipation and abdominal pain. ${ }^{13}$ Titrating the dosage slowly upward helped relieve these adverse symptoms (Table 1). Loperamide is available as a liquid formulation that is useful for titrating low doses.

Loperamide has been found to be superior to diphenoxylate in reducing stool frequency and improving consistency of stools in patients with chronic diarrhea after intestinal resection ${ }^{15}$ and was more effective than bismuth subsalicylate in reducing the number of unformed stools for patients with acute traveler's diarrhea. ${ }^{16} \mathrm{Nu}$ merous small studies have concluded that the agent can 
Table 1. Dosing Guidelines for Common Fecal Incontinence Medications

\begin{tabular}{|c|c|c|c|}
\hline Medication & Precautions & Dosing & Adverse effects \\
\hline Loperamide & $\begin{array}{l}\text { Use cautiously in patients with } \\
\text { active inflammatory disease of } \\
\text { the colon or with infectious } \\
\text { diarrhea. }\end{array}$ & $\begin{array}{l}\text { Adult: } 4 \text {-mg initial dose; } \\
2 \mathrm{mg} \text { for each subsequent loose stool } \\
\text { up to } 16 \mathrm{mg} / \text { day. Maximum daily } \\
\text { dosage for children: } 3 \mathrm{mg} \text {, age } 2-5 \mathrm{yr} \text {; } \\
4 \mathrm{mg} \text {, age } 6-8 \mathrm{yr} ; 6 \mathrm{mg} \text {, age } 8-12 \mathrm{yr} \text {. } \\
\text { Titrate upward slowly. }\end{array}$ & $\begin{array}{l}\text { Overdosage may result in CNS } \\
\text { depression and paralytic ileus; } \\
\text { children may be more sensitive } \\
\text { to CNS effects. Other reported } \\
\text { effects include rash, dizziness, } \\
\text { fatigue, cramping, constipation, } \\
\text { dry mouth, nausea, and } \\
\text { vomiting. }\end{array}$ \\
\hline $\begin{array}{l}\text { Diphenoxylate and } \\
\text { difenoxin }\end{array}$ & $\begin{array}{l}\text { Use cautiously in patients with } \\
\text { active inflammatory disease of } \\
\text { the colon. }\end{array}$ & $\begin{array}{l}\text { Preparations contain } 25 \mu \mathrm{g} \text { atropine } \\
\text { sulfate per tablet with either } 2.5 \mathrm{mg} \\
\text { diphenoxylate or } 1 \mathrm{mg} \text { difenoxin } \\
\text { Dosing: } 2 \text { tablets initially and then one } \\
\text { tablet every } 3-4 \text { hours. }\end{array}$ & $\begin{array}{l}\text { Overdosage may produce } \\
\text { constipation, toxic megacolon } \\
\text { (if previous inflammation), and } \\
\text { CNS effects. Atropine may } \\
\text { cause anticholinergic effects } \\
\text { (dry mouth, blurred vision). } \\
\text { Other effects are drowsiness } \\
\text { and urinary retention. }\end{array}$ \\
\hline Alosetron & $\begin{array}{l}\text { Reintroduced/approved by the } \\
\text { Food and Drug Administration } \\
\text { as unlabeled investigational } \\
\text { agent for managing diarrhea in } \\
\text { women with IBS. }\end{array}$ & $\begin{array}{l}\text { Prescribing limited to physicians enrolled } \\
\text { in GlaxoSmithKline program. Dosing: } \\
1 \mathrm{mg} \text { daily; may be increased to } 1 \mathrm{mg} \\
\text { twice daily if no response after } 4 \\
\text { weeks. } \\
\text { Discontinue if no improvement at } 1 \mathrm{mg} \\
\text { twice daily after } 4 \text { weeks. }\end{array}$ & $\begin{array}{l}\text { Constipation with excessive } \\
\text { dosage. Ischemic colitis severe } \\
\text { enough to be fatal. }\end{array}$ \\
\hline Phenylephrine gel & $\begin{array}{l}\text { Experiments restricted to patients } \\
\text { who were not pregnant and did } \\
\text { not have ischemic heart } \\
\text { disease, aortic aneurysm, } \\
\text { inflammatory bowel disease, or } \\
\text { uncontrolled hypertension. }\end{array}$ & $\begin{array}{l}\text { In experiments, } 2.5-\mathrm{cm} \text { application at } \\
10 \%-30 \% \text { concentration had a } \\
\text { therapeutic effect for most patients at } \\
1 \text { hour. Exact concentration seems } \\
\text { more important to achieve initial effect; } \\
\text { lesser concentrations can maintain. }\end{array}$ & $\begin{array}{l}\text { Transient stinging or burning with } \\
\text { higher concentrations. }\end{array}$ \\
\hline
\end{tabular}

safely and effectively reduce noninfectious diarrhea in children. Fifty-three young children with acute diarrhea in a hospital setting who received $0.8 \mathrm{mg} \cdot \mathrm{kg}^{-1} \cdot$ day $^{-1}$ of loperamide recovered from their symptoms faster and regained weight faster than children who received 0.4 $\mathrm{mg} \cdot \mathrm{kg}^{-1} \cdot \mathrm{day}^{-1}$ or placebo. ${ }^{17}$

Specific benefits for loperamide in the treatment of fecal incontinence were observed in an early study by Read et al. that compared loperamide $4 \mathrm{mg}$ daily with placebo. ${ }^{18}$ These investigators found that loperamide reduced urgency and incontinence, increased anal canal resting pressure, and improved the ability to retain saline infused into the rectum. In another crossover study, Hallgren et al. showed that loperamide improved passive incontinence following proctocolectomy. ${ }^{19}$ Arnbjornsson et al. reported in an uncontrolled trial that loperamide improved continence in children following rectoplasty for high imperforate anus. ${ }^{20}$

\section{Diphenoxylate and Difenoxin}

These opioid derivatives inhibit intestinal motility and propulsion. Because they cross the blood-brain barrier and can cause mild euphoria, atropine is added in subtherapeutic amounts to reduce the potential for over- dose and abuse. As antidiarrheal agents, diphenoxylate and difenoxin exhibit a slightly more potent effect than morphine but are not nearly as potent as loperamide. Both agents are appropriate for adult and pediatric populations.

Despite their generally favorable safety profiles, diphenoxylate and difenoxin in high doses can produce adverse CNS effects and the adjunctive atropine may cause anticholinergic effects. Excessive use or overdose may cause constipation and, if inflammatory conditions preexist, may promote the development of toxic megacolon.

Few large, double-blind, controlled trials have compared diphenoxylate and difenoxin with other antidiarrheal agents or placebo. Fifteen patients with chronic diarrhea and fecal incontinence treated either with diphenoxylate plus atropine or placebo experienced no effect on rectal or anal sphincter pressures, but the diphenoxylate-treated patients had reduced stool frequency and stool volume. ${ }^{21}$ The investigators recommended the agent for temporary or intermittent therapy. Diphenoxylate did not prove superior to kaolin-pectin suspension formulas in reducing the frequency of bowel movements, fluid content, or stool volume in 80 children with acute diarrheal illness. ${ }^{21}$ 


\section{Bulk-Forming and Hydroscopic Agents}

Although these agents are used for constipation, they can also alleviate mild chronic diarrhea by absorbing water and increasing stool bulk and possibly by creating the perception of decreased stool fluidity. Kaopectate, an over-the-counter preparation containing activated attapulgite, can relieve mild symptoms of diarrhea by decreasing the fluidity of the stool. Bliss et al. showed in a controlled study that fiber supplements (psyllium and gum agar) were more effective than placebo in reducing incontinence for patients who had fecal incontinence or loose or watery stools; the improvements were associated with more formed stools. ${ }^{22}$

\section{Bismuth Salicylate}

This combination of bismuth and subsalicylate suspended in a mixture of magnesium aluminum silicate clay seems to inhibit secretions, inflammation, and microbial development. Bismuth salicylate has been effective in preventing and treating traveler's diarrhea, and it may alleviate symptoms of nonsyndromic, episodic diarrhea. It is safe if taken at recommended dosages. The agent is not nearly as potent as loperamide and in headto-head, open-label comparisons was not as effective as loperamide in treating acute nondysenteric traveler's diarrhea $^{16}$ and acute diarrhea. ${ }^{23}$

\section{Phenylephrine Gel}

Phenylephrine gel is not currently approved for the treatment of fecal incontinence but is being tested in clinical trials. Phenylephrine is a selective $\alpha_{1}$-adrenergic agonist used as a nasal decongestant and as a vasoconstrictor in hypotension. The agent resembles naturally occurring catecholamines and can interact with $\alpha_{1}$ - or $\beta_{1}$-adrenergic receptors to produce sympathomimetic effects. ${ }^{24}$ Phenylephrine gel modulates the extrinsic innervation (vascular smooth muscle tissue) of the internal anal sphincter muscles to increase anal sphincter tone and help maintain anal canal resting pressure. The agent thus holds promise for subjects with passive fecal incontinence who have intact internal anal sphincter muscles associated with low resting anal sphincter pressure.

In 1999, British researchers initially applied the agent to 12 healthy volunteers and found a dose-dependent increase in maximum resting anal pressure, including a $33 \%$ increase with the use of $10 \%$ topical gel. ${ }^{25}$ There was no further improvement at concentrations $>30 \%$. However, in a subsequent trial ${ }^{26}$ involving 10 patients with weak but intact internal anal sphincter muscles and passive fecal incontinence, they applied phenylephrine gel concentrations of $10 \%, 20 \%, 30 \%$, and $40 \%$ or placebo gel to the anus. There was a clear dose-response relationship at 1 hour after application, and at both 1 and 2 hours, maximum anal resting pressure (MRP) was increased with all concentrations of the pheylephrine gel; the increase was statistically significant $(P<0.05$ compared with placebo) with the $30 \%$ and $40 \%$ concentrations, and median MRP values reached the normal range (Figure 1). Side effects were minimal, and for all patients, local discomfort settled within 20 minutes. The outcomes suggest that the exact initial concentration may be important for saturating relevant receptors throughout the anoderm. The investigators concluded that phenylephrine gel has the potential to achieve a sustained clinical response in subjects who have passive or urge incontinence but intact, functioning sphincters. The agent may possibly improve function for persons with structural damage to the sphincter. ${ }^{26}$

\section{Amitriptyline}

This older tricyclic antidepressant (which possesses anticholinergic, serotonergic, and antimuscarinic properties that affect the functions of the colon, rectum, and anal sphincter) has been used empirically to improve symptoms for patients with idiopathic fecal incontinence or IBS. ${ }^{27,28}$ The promise of low-dose amitriptyline is its ability to reduce the amplitude and frequency of rectal motor complexes, periods of powerful phasic contractions, possibly through an anticholinergic mechanism.

In an open-label study, 18 patients ( 2 men) with idiopathic fecal incontinence who received low-dose (20 mg daily) amitriptyline for 4 weeks and 24 healthy control subjects who did not receive the agent were evaluated. ${ }^{29}$ Treatment prolonged colonic transit time and led to the formation of firmer stools that were passed more frequently. Sixteen of the 18 amitriptyline-treated patients $(89 \%)$ had statistically significant improvements in incontinence scores, from a median of 16 (on a scale from 1 to 18 ) before treatment to a median of 3 after treatment $(P<0.001)$. Thirteen patients $(72 \%)$ had full remission of symptoms with complete stool control at 6-month follow-up. Treatment significantly reduced the amplitude (median rectal pressure, 94 vs. $58 \mathrm{~cm} \mathrm{H}_{2} \mathrm{O}$ ) and frequency ( 4.5 vs. 1.2 per hour; $P<0.01$ ) of rectal motor complexes as assessed by 24-hour ambulatory anorectal manometry. Santoro et al. also found that amitriptyline possibly diminished the increased anorectal pressures exerted during rectal motor complexes that may overcome sphincter resistance and cause incontinence. ${ }^{29}$ A randomized, placebo-controlled, variabledose, multicenter trial is needed to determine whether amitriptyline can alter rectal function as an independent factor contributing to fecal incontinence. 

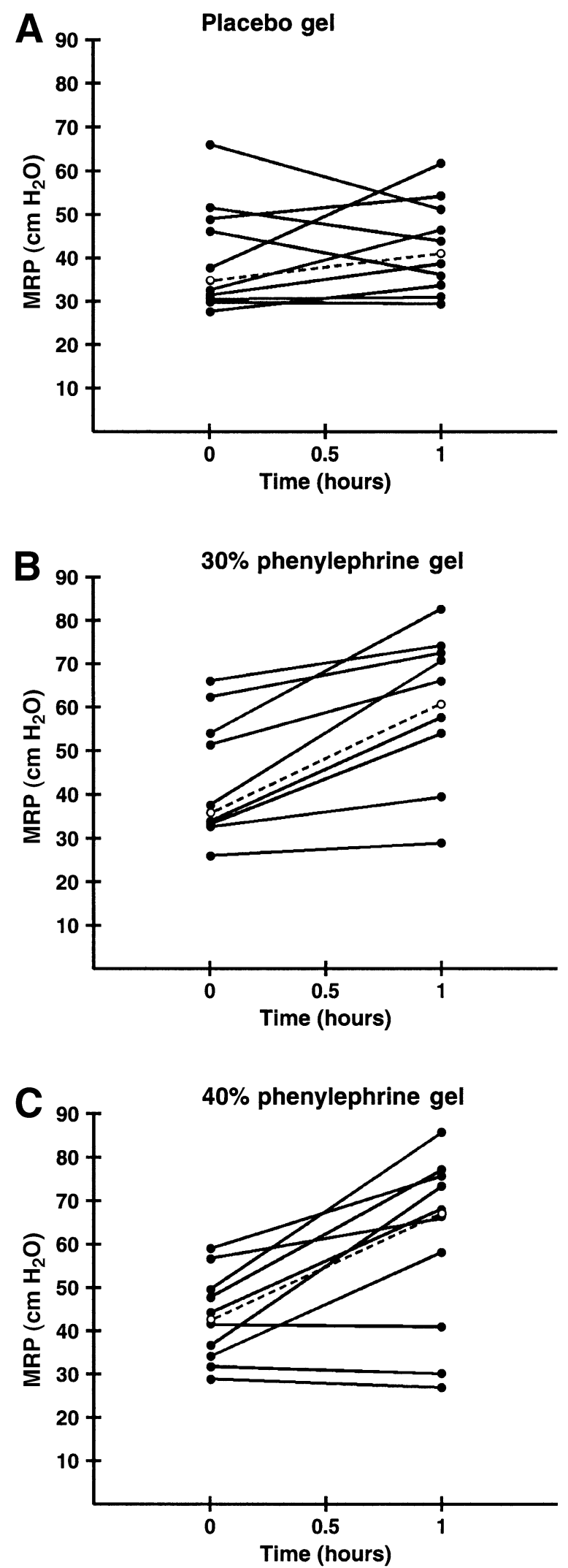

Figure 1. Effect of a single application of placebo gel or phenylephrine gel on maximum anal resting pressure (MRP) in 10 patients with fecal incontinence, measured before and 1 hour after application (broken line represents median values). ( $A$ ) Patients were given placebo gel. (B) Patients were given 30\% phenylephrine gel. (C) Patients were given 40\% phenylephrine gel. Adapted and reprinted with permission from Cheetham et al. 26

\section{5- $\mathrm{HT}_{3}$ Receptor Antagonists}

The $5-\mathrm{HT}_{3}$ receptor antagonists such as alosetron and cilansetron appear to inhibit the excitatory effects of $5-\mathrm{HT}_{3}$ receptors on both ascending and descending neuronal pathways involved in peristalsis. By slowing colonic transit, increasing "compliance" of the colon to distention, and decreasing visceral hypersensitivity, $5-\mathrm{HT}_{3}$ antagonists may be appropriate for treating patients with diarrhea-predominant IBS. Table 2 lists the mechanisms by which these agents are believed to influence gastrointestinal tract function. ${ }^{30}$

\section{Alosetron}

After being approved by the U.S. Food and Drug Administration in February 2000, alosetron was found to cause occasional severe side effects of ischemia and constipation. Physicians must now sign an agreement pledging that they understand how to diagnose and treat IBS and how to prescribe alosetron. Patients must also sign an agreement that they acknowledge the risks of taking alosetron. Prescriptions now have cautionary labeling, and recommended dosages have been halved. ${ }^{31}$ Although alosetron is an effective antidiarrheal agent, there are no reported data showing that it improves continence.

\section{Medical Management of Constipation}

Constipation has traditionally been difficult to define because of great variation in symptomatology. Constipation with pelvic floor outlet obstruction or pelvic floor dyssynergia can contribute to fecal impaction with resultant overflow incontinence, as can medications such as narcotic analgesics and antimotility drugs. Generally, constipation is defined as $\leq 3$ bowel movements per week, difficulty initiating or passing stools, passage of exceedingly firm or small-volume stools, straining, or a feeling of incomplete evacuation.

Cases of transient, benign constipation are highly treatable and can usually be traced to reversible factors such as immobility, lack of dietary fiber, poor fluid intake/dehydration, and the concurrent use of constipating drugs. Cases of chronic constipation may be more challenging to treat, because there may be underlying systemic disease or neurologic dysfunction contributing to the constipation. Treating physicians should seek to isolate the underlying pathophysiology either as delayed colonic transit (colonic inertia, slow-transit idiopathic constipation) or as a defecation (evacuation) disorder, which may be related to neurologic dysfunction or inappropriate relaxation of the pelvic floor when attempting to evacuate. ${ }^{32}$ Pelvic floor disorders affect women dispro- 
Table 2. Mechanisms by Which $5-\mathrm{HT}_{3}$ Receptor Antagonists May Influence Gastrointestinal Tract Function

\begin{tabular}{|c|c|c|}
\hline $\begin{array}{l}\text { Function/location } \\
\text { of receptors }\end{array}$ & Proposed mechanism & Expected effect \\
\hline \multicolumn{3}{|l|}{ Motility } \\
\hline \multirow[t]{2}{*}{ Excitatory enteric neurons } & $\begin{array}{l}\text { Reduced transmitter release } \\
\text { (e.g., acetylcholine, tachykinin) }\end{array}$ & Reduced ascending contraction (inhibition of peristalsis) \\
\hline & & Enhanced compliance \\
\hline Inhibitory enteric neurons & Reduced transmitter release & Reduced descending relaxation (inhibition of peristalsis) \\
\hline \multicolumn{3}{|l|}{ Visceral sensitivity } \\
\hline \multirow{2}{*}{$\begin{array}{l}\text { Sensory neurons } \\
\quad \text { (intrinsic and extrinsic) }\end{array}$} & Reduced transmitter release & Intrinsic neurons: peristalsis triggered at higher thresholds \\
\hline & & $\begin{array}{l}\text { Extrinsic neurons: reduced visceral nociception and } \\
\text { inhibition of reflex behaviors induced by intestinal } \\
\text { distention (e.g., variations in blood pressure) }\end{array}$ \\
\hline \multicolumn{3}{|l|}{ Absorption/secretion } \\
\hline $\begin{array}{l}\text { Secretomotor neurons and } \\
\text { enterochromaffin cells }\end{array}$ & Reduced transmitter/mediator release & $\begin{array}{l}\text { Increased absorption/reduced secretion; inhibition of } \\
\text { carcinoid-induced diarrhea }\end{array}$ \\
\hline \multicolumn{3}{|r|}{ 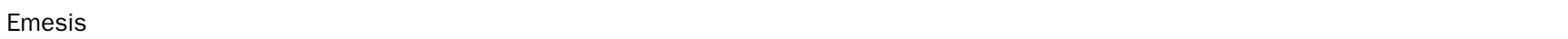 } \\
\hline $\begin{array}{l}\text { Enteric and CNS neurons; } \\
\text { enterochromaffin cells }\end{array}$ & $\begin{array}{l}\text { Blockade of effects of chemotherapy-induced } \\
\text { release of serotonin }\end{array}$ & Antiemetic effect \\
\hline
\end{tabular}

Adapted and reprinted with permission from Mayer et al. ${ }^{30}$

portionately and are usually accompanied by excessive straining during defecation and a sense of incomplete rectal emptying. Retained stool can decrease the internal anal sphincter pressure and allow liquid stool to seep from the anal canal, causing fecal incontinence.

Laxatives are used in the management of constipation and act in one of 3 ways: by retaining intraluminal fluid through hydrophilic or osmotic mechanisms, decreasing net fluid absorption and thereby altering small and large bowel fluid and electrolyte transport, or affecting motility either through the inhibition of segmental (nonpropulsive) contractions or the stimulation of propulsive contractions. ${ }^{33}$ Bulking agents, laxatives, and stool softeners must be used cautiously so as not to loosen stools excessively and exacerbate anal incontinence, particularly if anal sphincter pressures are lowered.

Laxative regimens have been shown to improve fecal incontinence both for children ${ }^{34,35}$ and institutionalized adults. ${ }^{36}$ Stimulant laxatives and polyethelene glycol seem to work better than enemas.

\section{Dietary Fiber}

Many cases of mild or transient constipation can be relieved by increasing dietary fiber intake to increase stool weight and soften the consistency of stools. Wheat bran has high lignin content, which increases stool weight. Psyllium husk, derived from the plantago seed, is a common ingredient in commercial fiber agents. Synthetic celluloses such as methylcellulose and polycarbophils are poorly fermentable compounds that help absorb water and increase stool bulk. Abdominal pain and bloating, the 2 most common adverse symptoms of greater fiber intake, usually decrease over time and may be avoided by increasing intake gradually. Consumption of fiber is contraindicated if the patient has obstructive symptoms or fecal impaction. ${ }^{33,37}$ In one study, patients with chronic constipation who had slow gastrointestinal transit or other defecation disorders were less likely to respond to dietary fiber therapy than patients who did not exhibit an underlying pathology. ${ }^{37}$

\section{Nonabsorbable Sugars and Alcohols}

Lactulose and sorbitol, nonabsorbable sugars that are hydrolyzed into organic acids, draw water osmotically into the intestinal lumen to stimulate colonic propulsion and motility. Lactulose and sorbitol have been shown to be equally effective in relieving idiopathic constipation in elderly subjects; lactulose is less expensive. The agents may not take effect for $24-48$ hours, during which time patients may experience abdominal discomfort or distention or flatulence that usually abates with continued treatment. ${ }^{33}$ When administered rectally, glycerin, a trihydroxy alcohol, promotes water retention to stimulate peristalsis and usually produces a bowel movement within an hour. It may cause mild rectal discomfort, a burning sensation, and minimal bleeding.

\section{Saline Laxatives}

The phosphate anions or magnesium cations in saline laxatives (sodium phosphate, magnesium sulfate, magnesium citrate, and magnesium hydroxide) are believed to mediate water retention osmotically to stimulate peristalsis. Magnesium may also stimulate the release of inflammatory mediators that boost the production of intraluminal fluids and electrolytes that increase intestinal motility. Because sodium phosphate is 
better absorbed than magnesium compounds, it needs to be administered in larger doses for therapeutic effect. Saline laxatives are well tolerated but should be used cautiously in patients with cardiac disease, renal insufficiency, or electrolyte abnormalities.

\section{Tegaserod and Cisapride}

Tegaserod, a partial $5-\mathrm{HT}_{4}$ agonist, accelerates small intestinal and colonic transit by boosting the peristaltic reflex and by decreasing visceral sensitivity in the upper and lower gastrointestinal tract. It has been shown to improve symptoms of abdominal pain, bloating, and constipation for persons with constipation-predominant IBS. A large placebo-controlled trial ${ }^{38}(\mathrm{n}=1519)$ of women with constipation-predominant IBS concluded that $12 \mathrm{mg} /$ day of tegaserod significantly improved constipation and abdominal pain and bloating. Another large, long-term trial ${ }^{39}$ involving 579 patients with IBS with constipation confirmed this finding. Despite its potential for treating incontinence associated with constipation, there are no reported data on the effects of tegaserod on incontinence.

Cisapride, a mixed $5-\mathrm{HT}_{3}$ antagonist $/ 5-\mathrm{HT}_{4}$ agonist, stimulates motor activity throughout the gastrointestinal tract by enhancing the release of acetylcholine from the enteric nervous system. However, it was not found to be effective for treating constipation. ${ }^{40,41}$ Moreover, safety concerns $^{42}$ have resulted in severe restrictions being placed on prescribing cisapride, so the drug has no role in the clinical management of constipation. Erythromycin is often used to stimulate gastrointestinal motility, although this is an off-label use of the drug. There is no evidence to support its use in the treatment of constipation.

\section{Fecal Impaction With Overflow Incontinence}

Impaction usually occurs in the distal colon and produces lower abdominal pain and a distended and highly compliant rectum; it sometimes results in incontinence as the internal anal sphincter relaxes in response to pressure from the fecal bolus. Impaired anorectal sensation, lower anal squeeze pressures, reduced integrity of sphincter and/or pelvic floor muscles, and neurogenic abnormalities are factors that may promote incontinence in the presence of fecal impaction. ${ }^{43}$

Fecal impaction may require manual removal of stool from the rectum as a first step in treatment. Further management may include taking steps to treat constipation such as increasing fiber intake, fluid intake, and physical activity. Constipation that does not respond to these measures may require the judicious use of stool softeners, laxatives, tap-water enemas, and possibly the use of rectal suppositories. Enema and suppository use should be limited to 2-3 times weekly. Anticholinergic and other medications that lead to constipation and impaction should be reduced in dosage or, if possible, eliminated.

A study by Chassagne et al. suggests that elimination of fecal impaction is critical to improving continence in incontinent nursing home residents with constipation. ${ }^{36}$ They studied 206 patients with daily fecal incontinence associated with fecal impaction and compared a single osmotic laxative with osmotic laxatives plus weekly enemas. Although the enemas did not significantly improve outcomes overall, periodic digital examination showed that the patients who achieved complete rectal emptying had $35 \%$ fewer episodes of fecal incontinence than the subjects who continued to experience fecal impaction.

\section{Prolapsing Hemorrhoids}

Hemorrhoids are blood vessels in the anal canal that arise from the hemorrhoidal cushion or plexus originating from the superior and inferior hemorrhoidal veins. Hemorrhoids may be internal or external. Internal hemorrhoids may prolapse from the anal canal due to the pressure of straining during bowel movements, diarrhea, sitting for extended periods, pregnancy, and childbirth. Prolapsing hemorrhoids may partially obstruct defecation and can cause soilage from the passage of fecal material, mucus, or blood. ${ }^{44}$ It is estimated that half of the patients with prolapsing (grades III and IV) hemorrhoids experience staining of undergarments with fecal material.

Mild cases of hemorrhoids can be relieved by increasing dietary fiber and fluid intake, bathing the anus, or applying soothing creams or ointments. Hemorrhoidectomy is an effective method for treating more severe cases. Recent advances in endoscopic evaluation and treatment have made it possible to obliterate hemorrhoids through banding ligation. In this procedure, the clinician, using a ligator attached to an endoscope or inserted through an anoscope, places a tight band around the enlarged vein, causing the hemorrhoid to thrombose. ${ }^{45}$ In addition to allowing the hemorrhoid to thrombose, ligation banding eliminates redundant mucosal tissue and produces submucosal scarring, which decreases the risk of fecal incontinence secondary to prolapsing tissue.

Preliminary trial results with this type of procedure have been promising. In one study, 34 of 39 patients 
(87\%) with either stage II or stage III hemorrhoids had no further bleeding complications after a single banding session. ${ }^{46}$ Other investigators found that patients with stage II hemorrhoids were more likely than patients with stage III hemorrhoids to achieve excellent results $(80 \%$ vs. $54 \%$ ) through endoscopic banding. ${ }^{47}$ Effects on fecal incontinence were not reported.

\section{Conclusion}

Treatment of fecal incontinence should focus on evaluating the patient, determining the underlying pathology, and choosing an appropriate medical therapy to provide symptomatic relief. For patients with diarrhea, ingestion of fiber and stool-bulking supplements can help form firmer stools. Medications such as loperamide and diphenoxylate that slow gastrointestinal transit time, reduce stool frequency, inhibit peristalsis, and increase sphincter tone and resting pressure are beneficial for managing diarrhea. For patients with constipation and overflow incontinence, judicious use of stool softeners, bulking agents, stimulant laxatives, and saline laxatives can help soften stool consistency, increase stool bulk, and decrease colonic transit time, thereby decreasing the risk of fecal impaction.

Recent advances in endoscopic hemorrhoidal banding have made it possible to more effectively remove prolapsing hemorrhoids to eliminate obstruction to defecation and reduce fecal soilage. Further studies are needed to specifically assess the effects of endoscopic banding on fecal incontinence.

Because the pathophysiology of fecal incontinence is often complex, future trials should assess the viability of using multiple pharmacologic interventions simultaneously. Multidisciplinary trials comparing combinations of surgical, medical, and behavioral interventions are also needed.

\section{References}

1. Nelson R, Norton N, Cautley E, Furner S. Community based prevalence of anal incontinence. JAMA 1995;274:559-561.

2. Drossman DA, Li Z, Andruzzi E, Temple RD, Talley NJ, Thompson WG, Whitehead WE, Janssens J, Funch-Jensen P, Corazziari E, Richter JE, Koch GG. US householder survey of functional gastrointestinal disorders. Prevalence, sociodemography, and health impact. Dig Dis Sci 1993;38:1569-1580.

3. Nelson R, Furner S, Jusadason V. Fecal incontinence in Wisconsin nursing homes: prevalence and associations. Dis Colon Rectum 1998;41:1226-1229.

4. Dey AN. Characteristics of elderly nursing residents: data from the 1995 National Nursing Home Survey. Adv Data 1997;289: $1-8$.

5. Burnett C, Whitehead WE, Drossman D. Psychological distress and impaired quality of life in patients with functional gastrointestinal disorders (abstr). Gastroenterology 1998;114:A729.

6. Rockwood TH, Church JM, Fleshman JW, Kane RL, Mavrantonis C,
Thorson AG, Wexner SD, Bliss D, Lowry AC. Fecal Incontinence Quality of Life Scale: quality of life instrument for patients with fecal incontinence. Dis Colon Rectum 2000;43:9-17.

7. Chassagne P, Landrin I, Neveu C, Czernichow P, Bouaniche M, Doucet J, Denis P, Bercoff E. Fecal incontinence in the institutionalized elderly: incidence, risk factors, and prognosis. Am J Med 1999;106:185-190.

8. Levine MD. Children with encopresis: a descriptive analysis. Pediatrics 1975;56:412-416.

9. Whitehead WE, Wald A, Norton NJ. Treatment options for fecal incontinence. Dis Colon Rectum 2001;44:131-144.

10. Jafri S, Pasricha PJ. Agents used for diarrhea, constipation, and inflammatory bowel disease; agents used for biliary and pancreatic disease. In: Hardman JG, Limbird LE, eds. Goodman \& Gilman's the pharmacological basis of therapeutics. 10th ed. New York: McGraw-Hill, 2001:1037-1058.

11. Ruppin $\mathrm{H}$. Loperamide-a potent antidiarrhoeal drug with actions along the alimentary tract. Aliment Pharmacol Ther 1987;1:179 190.

12. Musial F, Enck P, Kalveram KT, Erckenbrecht JF. The effect of loperamide on anorectal function in normal healthy men. J Clin Gastroenterol 1992;12:321-324.

13. Palmer KR, Corbett CL, Holdsworth CD. Double-blind cross-over study comparing loperamide codeine and diphenoxylate in the treatment of chronic diarrhea. Gastroenterology 1980;79:12721275.

14. Read MG, Read NW, Duthie HL. Effect of loperamide in anal sphincter function in patients with diarrhea (abstr). Gut 1979; 20:A942.

15. Bergman L, Djarv L. A comparative study of loperamide and diphenoxylate in the treatment of chronic diarrhea caused by intestinal resection. Ann Clin Res 1981;13:402-405.

16. Johnson PC, Ericsson CD, DuPont HL, Morgan DR, Bitsura JA, Wood LV. Comparison of loperamide with bismuth subsalicylate for the treatment of acute traveller's diarrhea. JAMA 1986;255: 757-760.

17. Karrar ZA, Abdulla MA, Moody JB, Macfarlane SB, Al Bwardy M, Hendrickse RG. Loperamide in acute diarrhea in childhood: results of a double-blind, placebo controlled clinical trial. Ann Trop Paediatr 1987;7:122-127.

18. Read M, Read NW, Barber DC, Duthie HL. Effects of loperamide on anal sphincter function in patients complaining of chronic diarrhea with fecal incontinence and urgency. Dig Dis Sci 1982; 27:807-814.

19. Hallgren T, Fasth S, Delbro DS, Nordgren S, Oresland T, Hulten L. Loperamide improves anal sphincter function and continence after restorative proctocolectomy. Dig Dis Sci 1994;39:26122618.

20. Arnbjornsson E, Breland U, Kullendorff CM, Okmian L. Effect of loperamide on faecal control after rectoplasty for high imperforate anus. Acta Chir Scand 1986;152:215-216.

21. Portnoy BL, DuPont HL, Pruitt D, Abdo JA, Rodriguez JT. Antidiarrheal agents in the treatment of acute diarrhea in children. JAMA 1976;236:844-846.

22. Bliss DZ, Jung HJ, Savik K, Lowry A, LeMoine M, Jensen L, Werner C, Schaffer K. Supplementation with dietary fiber improves fecal incontinence. Nurs Res 2001;50:203-213.

23. DuPont HL, Flores Sanchez J, Ericsson CD, Mendiola Gomez J, DuPont MW, Cruz Luna A, Mathewson JJ. Comparative efficacy of loperamide hydrochloride and bismuth subsalicylate in the management of acute diarrhea. Am J Med 1990;88:15S-19S.

24. Hoffman BB, Taylor P. Neurotransmission: the autonomic and somatic motor nervous system. In: Hardman JG, Limbird LE, eds. Goodman \& Gilman's the pharmacological basis of therapeutics. 10th ed. New York: McGraw-Hill, 2001:146.

25. Carapeti EA, Kamm MA, Evans BK, Phillips RKS. Topical phenyl- 
ephrine increases anal sphincter pressure. Br J Surg 1999;86: 267-270.

26. Cheetham MJ, Kamm MA, Phillips RKS. Topical phenylephrine increases anal canal resting pressure in patients with faecal incontinence. Gut 2001;48:356-359.

27. Ritchie JA, Truelove SC. Comparison of various treatment for irritable bowel syndrome. BMJ 1980;281:1317-1319.

28. Farrar JT. The effects of drugs on intestinal motility. Clin Gastroenterol 1982;11:673-681.

29. Santoro GA, Eitan BZ, Pryde A, Bartolo MS. Open study of lowdose amitriptyline in the treatment of patients with idiopathic fecal incontinence. Dis Colon Rectum 2000;43:1676-1682.

30. Mayer EA, Berman S, Derbyshire SW, Suyenobu B, Chang L, Fitzgerald L. The effect of the 5-HT3 receptor antagonist, alosetron, on brain responses to visceral stimulation in irritable bowel syndrome patients. Aliment Pharmacol Ther 2002;16: 1357-1366.

31. U.S. lets drug tied to deaths back on market. Available at: http://www.pharmacy forum.com/Lotronex. Accessed December 15, 2002.

32. Nygaard IE. Pharmacologic management of pelvic floor dysfunction. Obstet Gynecol Clin North Am 1998;25:867-882.

33. Jafri S, Pasricha PJ. Agents used for diarrhea, constipation, and inflammatory bowel disease; agents used for biliary and pancreatic disease. In: Hardman JG, Limbird LE, eds. Goodman \& Gilman's the pharmacological basis of therapeutics. 10th ed. New York: McGraw-Hill, 2001:1043.

34. van der Plas RN, Benninga MA, Buller HA, Bossuyt PM, Akkermans LM, Redekop WK, Taminiau JA. Biofeedback training in treatment of childhood constipation: a randomised controlled study. Lancet 1996;348:776-780.

35. Nolan T, Catto-Smith T, Coffey C, Wells J. Randomised controlled trial of biofeedback training in persistent encopresis with anismus. Arch Dis Child 1998;79:131-135.

36. Chassagne P, Jego A, Gloc P, Capet C, Trivalle C, Doucet J, Denis $P$, Bercoff $E$. Does treatment of constipation improve faecal incontinence in institutionalized elderly patients? Age Ageing 2000;29:159-164.

37. Voderholzer WA, Schatke W, Muhldorfer BE, Klauser AG, Birkner
B, Muller-Lissner SA. Clinical response to dietary fiber treatment of chronic constipation. Am J Gastroenterol 1997;92:95-98.

38. Prather CM, Camilleri M, Zinsmeister AR, McKinzie S, Thomforde G. Tegaserod accelerates orocecal transit in patients with constipation-related irritable bowel syndrome. Gastroenterology 2000;118:463-468.

39. Tougas G, Snape WJ Jr, Otten MH, Earnest DL, Langaker KE, Pruitt RE, Pecher E, Nault B, Rojavin MA. Long-term safety of tegaserod in patients with constipation-predominant irritable bowel syndrome. Aliment Pharmacol Ther 2002;16:1701-1708.

40. Farup PG, Hovdenak N, Wetterhus S, Lange OJ, Ovde O, Tronstad $\mathrm{R}$. The symptomatic effect of cisapride in patients with irritable bowel syndrome and constipation. Scand J Gastroenterol 1998; 33:128-131.

41. Schutze K, Brandstatter G, Dragosics B, Judmaier G, Hentschel $E$. Double-blind study of the effect of cisapride on constipation and abdominal discomfort as components of the irritable bowel syndrome. Aliment Pharmacol Ther 1997;11:387-394.

42. De Ponti F, Tonini M. Irritable bowel syndrome: new agents targeting serotonin receptor subtypes. Drugs 2001;61:317-332.

43. Rao SS, Welcher KD, Leistikow JS. Obstructive defecation: a failure of rectoanal coordination. Am J Gastroenterol 1998;93: 1019-1020.

44. Hemorrhoids. Available at: http://ekhsin.morehead-st.edu/aha/ crs/hem.htm. Accessed December 18, 2002.

45. Hemorrhoid banding. Available at: http://ekhsin.moreheadst.edu/aha/crs/hemban.htm. Accessed December 18, 2002.

46. Dickey W, Garrett D. Hemorrhoid banding using videoendoscopic anoscopy and a single-handed ligator: an effective, inexpensive alternative to endoscopic band ligation. Am J Gastroenterol 2000;95:1714-1716.

47. Berkelhammer C, Moosvi SB. Retroflexed endoscopic band ligation of bleeding internal hemorrhoids. Gastrointest Endosc 2002 55:532-537.

Address requests for reprints to: Yolanda V. Scarlett, M.D., Department of Medicine, Division of Gastroenterology and Hepatology, University of North Carolina School of Medicine, 1140-B Bioinformatics Building, CB 7080, Chapel Hill, North Carolina 27599. e-mail: yolanda_scarlett@med.unc.edu; fax: (919) 966-6842. 